Canadian Oncology

Nursing Journal

Revue canadienne

de soins infirmiers

en oncologie

Volume 30, Issue 2 • Spring 2020

elSSN: 2368-8076 


\title{
Taking control over our health: Empowerment as perceived by young adults living with advanced cancer
}

\author{
by Rosalind Garland, Saima Ahmed, and Carmen G. Loiselle
}

\begin{abstract}
Background: Health-related empowerment is a key concept in person-centred care. However, little is known of its core elements in young adults diagnosed with advanced cancer.
\end{abstract}

Objective: To explore empowerment in the context of young adults' healthcare experiences who are now in advanced stages of cancer.

Setting \& Participants: Twelve young adults (aged 21 to 39 years) were recruited from a large cancer centre in Montreal, Quebec.

Methods: In-depth interviews lasting between 36 and 90 minutes were conducted individually, audio-recorded, transcribed verbatim, and analyzed using thematic analysis.

Results: Throughout the cancer trajectory, participants reported a sustained desire to be actively involved in their treatment and care. Four themes emerged from the data representing processes of waiting, managing, acting, and revisiting. Subsumed under these were notions of body ownership, facing obstacles to care, optimizing health, and (re)considering their legacy.

Conclusions: Overall, participants wanted to remain in control of their situation despite the multiple challenges related to advanced cancer. If corroborated further, these findings should inform supportive cancer care approaches that are truly tailored to the needs of young adults.

Keywords: advanced cancer; cancer; empowerment; health-related empowerment; oncology; peer support; young adults

\section{AUTHOR NOTES}

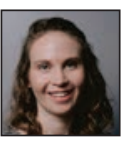

Rosalind Garland, RN, MSc(A), Medical Surgical Intensive Care

Unit, Jewish General Hospital, Montreal, QC

rosalind.garland@mail.mcgill.ca

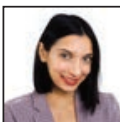

Saima Ahmed, BSc, Division of Experimental Medicine, McGill

University, Montreal, QC

Saima.ahmed2@mail.mcgill.ca

Carmen G. Loiselle, RN, PhD (Corresponding author), Affiliation: McGill University, Department of Oncology and Ingram School of Nursing, Montreal, QC; Segal Cancer Centre, Jewish General Hospital, Montreal, QC

Address: Ingram School of Nursing and Department of Oncology, Faculty of Medicine, McGill University, 680 Sherbrooke Ouest, Office 1812, Montréal, QC H3A 2M7

Email: carmen.g.loiselle@mcgill.ca; Tel: (514) 398-4163; Fax: (514) 398-8455

\section{INTRODUCTION}

pproximately 7,600 Canadian young adults (YAs) are Adiagnosed with cancer each year, making it the third leading cause of death in this group (Canadian Partnership Against Cancer, 2017; Statistics Canada, 2019). Evidence points to YAs' multiple unmet needs, as well as challenges related to delayed diagnosis, more aggressive disease, and higher cancer recurrence (Anders et al., 2009).

Typically, young adulthood-from the ages of 18 to 39 (Aubin et al., 2011) - is a developmental period marked by various transitions and age-related challenges, such as striving for autonomy and independence, higher education and new occupational roles, as well as romantic relationships and family planning (Shaw et al., 2015). Distinct from adolescence, YAs' cognitive and social development is thought to be further influenced by social and physical factors (Morgan et al., 2010). In oncology, young adults with cancer consistently report significant issues such as feeling lonely, being socially withdrawn, poor symptom management, feeling out of place in non-age-specific support groups, experiencing financial and family dependence, and in advanced stages, difficulties transitioning from being in a curative setting to being with those receiving more intensive palliative or even end-of-life care (Borneman et al., 2014; Trevino et al., 2013; Trevino et al., 2014). Young adults with advanced cancer also face significant psychological distress related to body image and sexual/reproductive issues (Morgan et al., 2010; Murphy et al., 2015; Zucchetti et al., 2017). Moreover, as the process of identity formation is still occurring, a diagnosis of advanced, chronic or incurable cancer often has a profound effect on one's personal identity (Kroger et al., 2010; Tindle, 2015; Trevino et al., 2012).

Recently, efforts have focused on an enhanced understanding of the experiences of young adults with advanced cancer and how personal and health-related resources can optimize their psychosocial adjustment outcomes (DePauw et al., 2019; Cheung \& Zebrack, 2017; Lea et al., 2018; Leuteritz et al., 2017; Quinn et al., 2015; Warner et al., 2018; Zebrack et al., 2013). Inherent to these processes is the centrality of empowerment, a concept whereby YAs are construed as active partners rather than passive recipients of care (Reed et al., 2017).

\section{HEALTH-RELATED EMPOWERMENT}

Health-related empowerment (HRE) is broadly defined as feelings of being able to manage one's own health condition and having a sense of control over health-related matters and care needs (Maunsell et al., 2014). HRE is closely linked to self-advocacy and engagement, with the latter associated with improved clinical outcomes, higher satisfaction with treatment 
decision-making and reduced healthcare costs (Coulter, 2012; Hibbard \& Greene, 2013; Jerofke et al., 2014;). As such, HRE is considered a core tenet of person-centred care, patient activation and self-management. More specifically, it is associated with an individual's sense of active engagement in life, acquisition of technical skills related to disease management, persistence of constructive attitudes and positive emotional well-being, as well as confidence in communicating and collaborating with healthcare professionals (Maunsell et al., 2014; Osborne et al., 2007).

In cancer, the multidimensional factors that give rise to HRE, and empowerment as a whole, have been linked to more positive health outcomes (Hibbard \& Greene, 2013; Jerofke et al., 2014; Maunsell et al., 2014; van den Berg et al., 2013). In addition, YAs living with advanced cancer who feel positive alliances with healthcare providers perceive greater social support, reduced illness-related grief and show better adherence to treatment (Trevino, Fasciano, \& Prigerson, 2013). However, a key challenge lies in establishing an overarching framework for HRE and identifying its key characteristics (Barr et al., 2015; Eskildsen et al., 2017; Maunsell et al., 2014; Zimmerman, 1995). Thus, it is timely to further explore HRE's core elements according to specific patient groups and contexts.

\section{HEALTH-RELATED EMPOWERMENT AND CANCER CARE}

Akin to the study of individuals living with a chronic illness, work by Maunsell et al. (2014) observed health-related empowerment factors in groups of patients coping with cancer. Social support, positive attitudes and satisfying relationships with healthcare providers were found to be significantly associated with higher levels of health-related empowerment, as were the acquisition of new cancer management skills and lower reported emotional distress (Maunsell et al., 2014). Research into factors influencing health-related empowerment in cancer also points to differences across diagnoses and age groups (Eskildsen et al., 2017; Mausnell et al., 2014; van den Berg et al., 2013; Zimmerman, 1995).

Some evidence and clinical observations also indicate that, despite advanced stages of cancer, many individuals wish to remain active partners in the management of their own cancer (Brom et al., 2014; Yennurajalingam et al., 2018). This extends to YAs who wish to be proactive in coping with cancer-related issues that affect them (Trevino et al., 2012). A study by Kaal et al. (2017) assessing HRE in young adults found positive relationships between HRE and self-awareness, the capacity to manage new situations, and social support, whereas coping difficulties were negatively associated with HRE. To identify promising HRE interventions that optimize cancer care experiences of young adults with advanced cancer, a better understanding is needed. Therefore, a qualitative inquiry was undertaken to provide new insights into YAs' opinions and experiences as they manage advanced stages of cancer.

\section{METHOD}

\section{Study questions and design}

This in-depth exploratory study was guided by the following research questions:
1. What key factors emerge in relation to a sense of health-related empowerment as described by young adults living with advanced cancer?

2. What are the perceived barriers and facilitators to health-related empowerment for these young adults?

\section{Participants, setting and procedures}

Recruitment took place at a large cancer centre in a McGill University-affiliated hospital in Montreal, Quebec. Ten females and two males, ranging from 21 to 39 years of age $(M=33)$ agreed to take part in the study. Table 1 provides participants' sociodemographic information. Following ethics approval, a convenience sampling strategy was used with local community organizations publicizing the study and asking potential participants if they would agree to have a research assistant contact them to discuss the study requirements. If young adults showed interest, the research assistant was informed and contact was made over the phone or in-person to provide further study details, answer questions and, if they agreed to participate, obtain written consent.

Inclusion criteria were: 1) having metastatic, chronic, or recurrent cancer of stage III or IV; 2) the ability to complete interviews in French or English; and 3) being 18-39 years of age. Exclusion criteria were: 1) having physical or cognitive limitations, such as extreme fatigue or difficulties with communication, that would prevent active participation in an interview, or 2) being at imminent "end-of-life", defined as a condition in rapid decline whereby active treatment is stopped, and considered in the actual process of dying (Jerofke et al., 2014).

Table 1. Sociodemographic characteristics of participants $(N=12)$

\begin{tabular}{|l|c|}
\hline Stage & 2 \\
\hline III & 8 \\
\hline IV & 2 \\
\hline Did not know/ Recurrence & \\
\hline Type & 2 \\
\hline Brain & 4 \\
\hline Breast & 1 \\
\hline Colorectal & 2 \\
\hline Hodgkin's Lymphoma & 1 \\
\hline Pancreatic & 1 \\
\hline Thyroid & \\
\hline Time since diagnosis & 3.2 years \\
\hline Mean & \\
\hline Education & 5 \\
\hline Technical/vocational & 7 \\
\hline Bachelor's or higher & \\
\hline & \\
\hline
\end{tabular}




\section{Data collection}

Once informed consent was obtained, data were collected by the first and senior authors. Data were collected using a semi-structured interview guide, an audio recorder, and participants completed a short socio-demographic and medical questionnaire.

The interview guide was developed following a thorough review of the literature on HRE and needs of young adults living with cancer (Appendix 1 - Interview Guide for Young Adults with Cancer). Furthermore, additional questions were inspired by the Heath Education Impact Questionnaire-a health-related empowerment tool developed by Osborne et al. (2007). Questions addressed factors such as social support, collaboration and decision-making with the medical team, acquisition of knowledge related to their disease, cancer care experiences, self-advocacy, healthcare system interactions or services that were beneficial or problematic, and support systems.

Participants met one-on-one with the researcher at a mutually agreed time and location. The locations included private meeting rooms at a hospital, local community support organization, or university, as well as participants' homes. Individual interviews took place between December 2015 and October 2016 and lasted between 36 and 90 minutes.

\section{Data analysis}

Qualitative data underwent thematic analysis, as outlined by Braun and Clarke (2006). First, audio recorded content was transcribed verbatim, followed by several thorough readings of the transcripts by the investigators to gain an in-depth understanding of the overall content of the interviews. Authors independently read and coded the initial transcripts, line by line, to highlight content related to the dimensions, barriers and facilitators of HRE. The transcripts were coded by one investigator, content/themes were then discussed and reviewed with the other investigator. Coded data were placed into meaningful categories and then organized into broader themes. As new themes emerged, previously coded data were re-examined to ensure accuracy until consensus was reached and no new themes emerged from the data. Participants were not asked to provide feedback on the findings.

To enhance transparency, descriptions of the study, sample and contextual factors were documented.

\section{FINDINGS}

\section{Key themes}

Data analysis revealed four main themes that describe how HRE was related to YAs working toward proactively managing their situation (Figure 1).

Theme 1. Wait, "This is my body": Being actively involved in decisions affecting the self

1.1 Facilitator: Maintaining control over decisions pertaining to their own body. Many participants discussed ownership of their body and having to live with the side effects of treatment as reasons for actively engaging in decision-making about health, and involvement in conversations related to risks and benefits of proposed cancer treatments. The sense of knowing one's body also determined, in some instances, their decision to continue treatment despite medical recommendations that it be discontinued. Body ownership was clearly described by a female participant who stated, "This is my body and if we are going to do anything [to it] or if you're going to decide anything, it's because I'm okay with it." (P4)

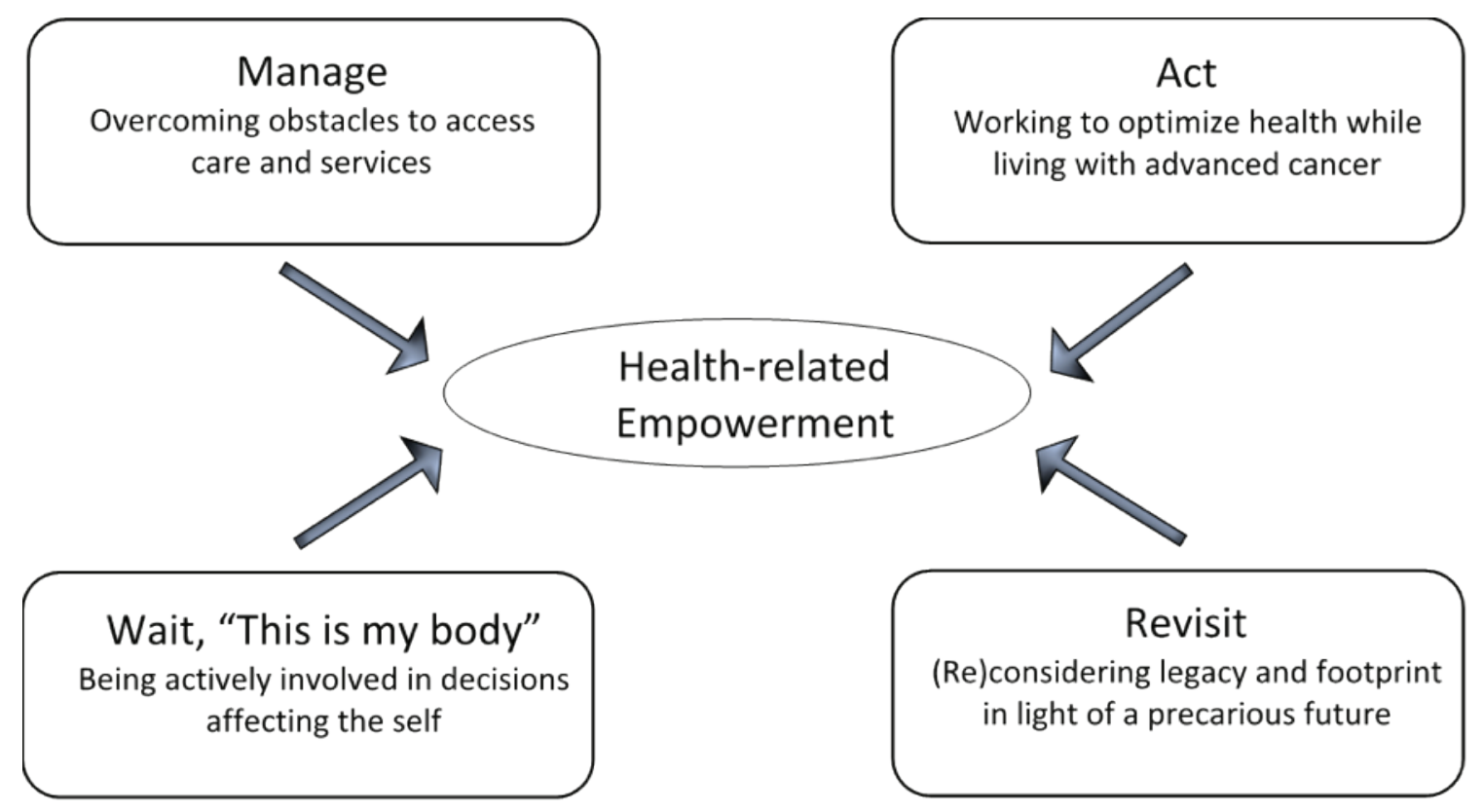

Figure 1. Key Themes that emerged from the qualitative thematic analysis 
Some felt that although it was difficult to maintain control over decisions related to treatment, it was still important to attempt to do so. Many described not wanting to be defined by their illness and highlighted that cancer should not unduly affect body image or how others construe participants' propensity to engage in strenuous activities. Young adults spoke of their continued participation in competitive sporting events, academic and work-related activities, adventure travels and family responsibilities despite living with debilitating side effects, treatment complications, and chronic fatigue.

\section{Theme 2. Manage: Overcoming obstacles to access care and services}

2.1 Barrier: Coping with interactions with the health care system. Participants described prior barriers to screening and diagnosis when healthcare providers discounted signs and symptoms reported by young adults. For instance, some firstline physicians minimized patients' concerns by suggesting that they were too young to worry about cancer. As stated by one female participant, "They kind of told me not to worry, because I'm young and it's probably nothing." (P7) Young adults also discussed negative interactions, which made them feel "powerless" (P9) or led them to mistrust the healthcare system. One participant described a situation where physicians misleadingly spoke of their prior experience with her type of cancer,

"I was very adamant that I really wanted my doctors to umm have experience and know what they were talking about [...] And they said they did. And they didn't, [...] which was not very easy [...] when I found out afterwards [...]." (P4)

On the other hand, young adults felt empowered when their voices were heard, their concerns addressed, and when they were welcomed as active partners in treatment-related conversations.

2.2 Barrier: Facing system-centric rather than person-centred health care. At times, participants felt that the healthcare system could be a significant barrier to them engaging in their own management of cancer. They reported a healthcare system that was more centred around professional and service needs rather than being patient-oriented. They were vocal about the importance of being their own advocate, despite their precarious health status including low energy levels, complications, and chronic fatigue. As one participant described,

"I think [...] the healthcare providers need to, uh, understand that [...] a patient [...] may perhaps have three appointments in one day. Let's try to keep the appointments within the same timeframe. Don't make me go back and forth [...] that puts a lot of, uh, time and effort into your, your system and [...] you're trying to save your life." (P1)

Additionally, some felt that hospital protocols were not adapted to personal situations and that their "voices" were often silenced. Participants also described issues with time restrictions during medical consultations and service gaps that left them feeling like a number rather than a partner in care. As described by one participant, "I get the feeling that [...] they just want to get it done, in and out and that's it, you know? [...] it's not a good feeling, [...] you feel more like a number than a person." (P7) In addition, participants discussed gaps in care and system disorganizationin terms of being "not well coordinated." (P1) As one participant described, "When I went in, he told me, I have to send you back, I lost your results." (P3)

\section{Theme 3. Act: Working to optimize health while living with} advanced cancer

3.1 Facilitator: Learning to navigate the cancer world. Participants spoke of the actions they undertook to navigate the world of cancer and sustaining their health and well-being. They described how they would actively put together a team of healthcare professionals or decide to substitute members when needed. One reasoned, "I truly believe that ultimately it's [...] my team and [that] I choose my team [...] and if there's someone on your team that you don't like, you are allowed to change them." (P6) Participants also spoke about the benefits of making difficult health care decisions and the impact on their feelings of control. One participant described, "I'm [...] so proud of myself and I know it takes efforts [...] just the fact that I was able to change hospitals, I'm so proud of myself (laughs) you know, I did something for my care." (P9) Furthermore, young adults described how they strategized to address gaps or delays in care. Some described learning about structural processes of the healthcare system and finding more efficient means (i.e., shortcuts such as direct smart phone messaging or faxing information directly to their doctors) to reduce delays and manage wait times. Participants also used contacts, such as family members, peers, friends and other patients to gain access to resources and complementary therapies that they thought would benefit them.

3.2 Facilitator: Selectively seeking cancer information when planning care. All participants expressed that having enough information was essential to take part in decisions about their care. Many described wanting all relevant cancer information at least at the time of diagnosis and treatment. On some occasions, information gathered enabled them to advocate for new treatment options. In contrast, two participants (P2, P4) limited cancer information seeking to manage their anxiety and fears. Also, preferences for cancer information were reported to change over time. A participant said,

"I think when I first got diagnosed with cancer, I was 24 hours with my nose in a book, or researching something on the internet, or trying to talk to someone and really understanding cancer as a whole [...] and now, the less I have, the better." (P4)

3.3 Barrier: Managing an uncertain future. All participants talked about the unpredictability linked to disease progression and its impact on their life goals. They spoke of learning to accept shorter-term, as opposed to long-term planning pertaining to recreational activities, future vacations, and duties. In some cases, physicians also acknowledged challenges related to a highly uncertain future. A participant said,

"My doctor [...] told me... she's like 'no one's going to blame you [...] your type of cancer is like having a guillotine over your head and not knowing when it's going to come down and kill you' although it's such a cruel comment, [...], it is the best visualization [...] of what I feel." (P4) 
Theme 4. Revisit: (Re)considering legacy and footprint in light of a precarious future

4.1 Facilitator: Balancing the need for independence and support needs. Participants reported attempting to balance their need to ask for help with their strivings for independence. This often involved accepting support from family and friends for activities of daily living, which required adjustment from the independence they held prior to having advanced cancer. All described, however, a sense of relief once they felt comfortable asking for help. By agreeing to receive external support, many realized that they had more energy for other important aspects of their lives. For instance, this person reported,

"I know that I am lucky because I have a good network of people around me, so [...] that gives me the energy to take care of all this, normally someone who does all the rest may not have the energy to [...] like to make all the calls, to go to the hospital." (P12)

4.2 Facilitator: Valuing peer connections. Young adults discussed their involvement in new roles within the cancer community. Some described supportive interactions with peers that appeared mutually beneficial,

"[The young adults] really emanate [...] that spirit of being empowered, approaching [...] your health [...] and [...] your treatment like that, it's something that inspires me [...] and motivates me to you know stay empowered [...] and I hope that I'm passing that on to the community as well." (P5)

Another stated, "I feel very happy because I am useful, even with my disease, I am still useful.” (P2)

Furthermore, young adults were proud of their contributions, such as starting new support groups, getting involved in fundraising, and participating in research.

4.3 Facilitator: Shaping a legacy. Many described the impact that cancer had on their thoughts of personal legacy. Although how young adults wanted to be remembered varied somewhat, similarities were also present. For many, legacy goals shifted and were quite different pre- and post-diagnosis. A male participant described:

"I think the legacies that I wanted to leave behind [...] were completely different than they are today. Umm before I guess I was more career oriented, I wanted to move up the corporate ladder, work hard, make a good living [...] and uh the legacy has changed, now I want to help people, I want to advocate, I want to inform, I want to help whoever has a similar uh diagnosis as me." (P1)

Additionally, young adults spoke about not wanting to waste time and doing things they always wanted to do. For those with children, they underscored, for instance, that teaching moral values to their kids became a priority.

\section{DISCUSSION}

This study offers unique insights into the experiences of young adults with cancer, as it pertains to feeling empowered even when facing advanced disease. The findings contribute to our understanding of context, barriers and facilitators that affect patients' propensity to self-manage while dealing with a precarious health status.

Participants reported being proactive in most aspects of their experience. These findings echo prior work on the importance for YAs to maintain control over health matters and be actively involved in managing their cancer (Howk \& Wasilewski-Masker, 2011). At a transitional development stage of independence, YAs also must cope with the burden associated with advanced disease and periodic dependence on others (Marris et al., 2011). The transformational aspect of cancer and the ability to manage symptom burden are key aspects of YAs' experience with cancer (Clark \& Fasciano, 2015). These needs and that of maintaining a sense of normalcy amidst challenges are also seen in the context of coping with chronic illnesses (D’Agostino, Penney \& Zebrack, 2011; Grinyer \& Thomas, 2001; Miedema, Hamilton, \& Easley, 2007). Negative interactions with healthcare providers and inflexible healthcare structures-also described in other oncology settings (Maunsell et al., 2014; Mulcahy et al., 2010; van den Berg et al., 2013)—were seen as significant barriers to empowerment. Power dynamics in healthcare have been reported to be increasingly challenging for individuals who desire to take on a more active role in cancer-related decisions (Bell et al., 2018; Berry et al., 2017).

Participants reported wanting to interact with peers who faced similar challenges - an observation also reported elsewhere, as patient expertise is increasingly recognized as distinct and valuable to peers affected by cancer (Haldar et al., 2018; Hartzler \& Pratt, 2011; Power \& Hegarty, 2010). Peer support/community organizations are increasingly sought out by patients, as they tend to actively promote empowerment through experiential sharing and psychosocial support, helping meet their information and emotional support needs (Ahmed, Harvey \& Amsellem, 2011; Campbell, Phaneuf \& Deane, 2004; Lau et al., 2015; Mirrielees et al., 2017; Saxton, Amsellem, Buzaglo, \& Hollen, 2017). Herein, the importance of personal legacy, namely how one wants to be remembered, was an important factor in feeling empowered and this has been reported by others (Breitbart et al., 2010; Clark \& Fasciano, 2015). Our findings highlight how participants engaged in a process of life review, underscoring their needs to leave behind a positive mark on others - a finding consistent with other reports among young cancer survivors (Clark \& Fasciano, 2015; Lewis et al., 2011; Tindle, 2015).

The themes that emerged in this study are closely linked to self-advocacy and engagement, which have been found to be key contributors to HRE (Coulter, 2012; Hibbard \& Greene, 2013; Jerofke et al., 2014; Kaal et al., 2017), with legacy also positively linked to empowerment in young adults (Keim-Malpass, Adelstein, \& Kavalieratos, 2015).

\section{STUDY CONTRIBUTIONS AND LIMITATIONS}

This study contributes to the limited body of literature focusing on the experiences of YAs with advanced cancer. Describing how YAs advocate for themselves within a publicly funded healthcare system begins to address knowledge gaps in YA research identified by Drake and Urquhart's (2019) scoping review. HRE described herein also echoes the themes identified by Drake and Urquhart. 
This in-depth inquiry reveals the needs of YAs to remain deeply engaged while dealing with functional challenges related to their advanced stage of disease. Detailed personal accounts underscore the relevance of HRE for this group. Clinicians must promote proactive behaviours in YAs while being cognizant of their changing needs and preferences. As nurses already play a key role in advocating and supporting patients, providing a climate where the voices of this unique group are heard by the multidisciplinary team is imperative, as is welcoming them as active partners in their treatment and care decisions.

Of note, there are a few limitations inherent to this study. Participants were at the upper end of the age spectrum for YAs, which may have coloured their narratives about empowerment. The presence of a YA program and a volunteer cancer organization within the study site may have influenced accounts of empowerment-related experiences.

Future research should elucidate how HRE in young adults with advanced cancer may further vary according to sex, gender, culture, sociodemographic context and education.

\section{REFERENCES}

Ahmed, I., Harvey, A., \& Amsellem, M. (2011). Frankly speaking about cancer: A national model of success for cancer education and patient education. American Public Health Association annual meeting, Washington, D.C., October 29-November 2, 2011.

Anders, C. K., Johnson, R., Litton, J., Phillips, M., \& Bleyer, A. (2009). Breast cancer before age 40 years. Seminars in oncology, 3, 237-249.

Aubin, S., Barr, R., Rogers, P., Schacer, B., Bielack, S. S, Ferrari, A., Manchester, R. A., Morgan, S., Patterson, M., Perlli, A. S., Ribera, J-M., Shaw, P., Thomas, D. M., Treadgold, C. (2011). What should the age range be for AYA oncology? Journal of adolescent and young adult oncology, 1, 3-IO.

Barr, P. J., Scholl, I., Bravo, P., Faber, M. J., Elwyn, G., \& McAllister, M. (2015). Assessment of patient empowerment-A systematic review of measures. PLoS ONE. 10, e0126553. https://doi.org/10.1371/ journal.pone.0126553.

Bell, S. K., Roche, S. D., Mueller, A., Dente, E., O’Reilly, K., Sarnoff Lee, B., Sands, K., Talmor, D., \& Brown, S. M. (2018). Speaking up about care concerns in the ICU: Patient and family experiences, attitudes and perceived barriers. BMJ Quality Q Safety, 11, 928-936.

Berry, L. L., Danaher, T. S., Beckham, D., Awdish, R. L. A., \& Mate, K. S. (2017). When patients and their families feel like hostages to health care. Mayo Clinic proceedings, 9, I373-138I.

Borneman, T., Irish, T., Sidhu, R., Koczywas, M., \& Cristea, M. (2014). Death awareness, feelings of uncertainty, and hope in advanced lung cancer patients: Can they coexist? Int J Palliat Nurs., 20, 27177. https://doi.org/10.12968/ijpn.2014.20.6.271

Braun, V., \& Clarke V. (2006). Using thematic analysis in psychology. Qual Res Psychol., 3, 77-101. https://doi. org/10.1191/1478088706qp063oa

Breitbart, W., Rosenfeld, B., Gibson, C., Pessin, H., Poppito, S., Nelson, C., Tomarken, A., Timm, A. K., Berg, A., Jacobson, C., Sorger, B., Abbey, J., \& Olden, M. (2010). Meaning-centered group psychotherapy for patients with advanced cancer: A pilot randomized controlled trial. Psycho-oncology, 1, 2I-28. https://doi. org/10.1002/pon.1556

Brom, L., Pasman, H. R., Widdershoven, G. A., van der Vorst, M. J., Reijneveld, J. C., Postma, T. J., \& Onwuteaka-Philipsen, B. D. (2014). Patients' preferences for participation in treatment

\section{AUTHOR DISCLOSURE STATEMENT}

There are no conflicts of interest for the authors

\section{ACKNOWLEDGEMENTS}

We would like to thank the young adults who generously gave of their time and shared their personal stories with us. We also acknowledge Hope a Cope-a vibrant community volunteer organization-for assisting in identifying potential participants, as well as Dr. Ariella Lang for providing feedback on earlier versions of this manuscript. The study was supported, in part, by graduate student awards to Rosalind Garland from the Canadian Institutes of Health Research, the Judith Anne Litvack Bursary, and the Maysie MacSporran Graduate Studentship. Dr. Loiselle's research is supported by the Christine a Herschel Victor/Hope a Cope Research Chair in Psychosocial Oncology at McGill University.

decision-making at the end of life: Qualitative interviews with advanced cancer patients. PloS one, 6, eIoo435.

Campbell, H. S., Phaneuf, M. R., \& Deane, K. (2004). Cancer peer support programs - do they work? Patient education and counseling, $1,3-\mathrm{I} 5$.

Canadian Partnership Against Cancer. (2017). Adolescents \& young adults with cancer: A system performance report. Toronto, Ontario: Canadian Partnership Against Cancer.

Cheung, C. K., \& Zebrack, B. (2017). What do adolescents and young adults want from cancer resources? Insights from a Delphi panel of AYA patients. Supportive Care Cancer. 25, 119-126. https://doi. org/10.1007/s00520-016-3396-7

Clark, J. K., \& Fasciano, K. (2015). Young adult palliative care: Challenges and opportunities. Am J Hosp Palliat Care. 32, 101-111. https://doi.org/10.1177/1049909113510394

Coulter, A. (2012). Patient engagement-What works? JACM, 35, 80-89. https://doi:10.1097/JAC.0b013e318249e0fd

D’Agostino, N. M., Penney, A., \& Zebrack, B. (2011). Providing developmentally appropriate psychosocial care to adolescent and young adult cancer survivors. Cancer, 10 Suppl, 2329-2334.

DePauw, S., Rae, C., Schacter, B., Rogers, P., \& Barr, R. D. (2019). Evolution of adolescent and young adult oncology in Canada. Current Oncology, 26, 228-233.

Drake, E. K., \& Urquhart, R. (2019). The experiences of young adults living with metastatic/advanced cancer: A scoping review. Journal of adolescent and young adult oncology. http://doi.org/10.1089/ jayao.2019.0093

Eskildsen, N. B., Joergensen, C. R., Thomsen, T. G., Ross, L., Dietz, S. M., Groenvold, M., \& Johnsen, A. T. (2017). Patient empowerment: A systematic review of questionnaires measuring empowerment in cancer patients. Acta Oncol., 56, 156-165. https://doi.org/10.1080 /0284186x.2016.1267402

Grinyer, A., \& Thomas, C. (2001). Young adults with cancer: The effect of the illness on parents and families. International Journal of Palliative Nursing, 4, 162-4, 166-70.

Haldar, S., Mishra, S. R., Khelifi, M., Pollack, A. H., \& Pratt, W. (2018). Exploring the design of an inpatient peer support tool: Views of adult patients. AMIA ... Annual Symposium proceedings. AMIA Symposium, 1282-1291. 
Hartzler, A., \& Pratt, W. (2011). Managing the personal side of health: How patient expertise differs from the expertise of clinicians. Journal of Medical Internet Research, 3, e62.

Hibbard, J. H., \& Greene, J. (2013). What the evidence shows about patient activation: Better health outcomes and care experiences; fewer data on costs. Health Aff., 32, 207-214. https://doi. org/10.1377/hlthaff.2012.1061

Howk, T., \& Wasilewski-Masker, K. (2011). Palliative care for adolescents and young adults: A pediatric perspective. $J$ Adolesc Young Adult Oncol., 1, 11-12. https://doi.org/10.1089/ jayao.2011.1503

Jerofke, T., Weiss, M., \& Yakusheva, O. (2014). Patient perceptions of patient-empowering nurse behaviours, patient activation and functional health status in postsurgical patients with lifethreatening long-term illnesses. J Adv Nurs., 70, 1310-1322. https:// doi.org/10.1111/jan.12286

Kaal, S. E. J., Husson, O., van Duivenboden, S., Jansen, R., MartenHorst, E., Servaes, P., Prins, J. B., van den Berg, S. W., \& van der Graad, W. T. A. (2017). Empowerment in adolescents and young adults with cancer: Relationship with health-related quality of life. Cancer, 123, 4039-4047. https://doi.org/10.1002/cncr.30827

Keim-Malpass, J., Adelstein, K., \& Kavalieratos, D. (2015). Legacy making through illness blogs: Online spaces for young adults approaching the end-of-life. Journal of Adolescent and Young Adult Oncology, 4, 209-212.

Kroger, J., Martinussen, M., \& Marcia, J. E. (2010). Identity status change during adolescence and young adulthood: A metaanalysis. J Adolesc., 33, 683-698. https://doi.org/10.1016/j. adolescence.2009.11.002

Lau, G. J., Lapointe, J., Dalzell, M. A., Smirnow, N., Ibrahim, M., Beloff, E., Seguin, C., Tremblay, N., Duncan, L., O’Brien, S., \& Loiselle, C. G. (2015, October 4). The breast \& bone health program: A transdisciplinary model of care to proactively address bone health in breast cancer. Canadian Association of Nurses in Oncology annual conference. Toronto, Ontario, October 4-7, 2015.

Lea, S., Martins, A., Morgan, A., Cargill, J., Taylor, R. M., \& Fern, L. A. (2018). Online information and support needs of young people with cancer: Aparticipatory action research. Adolesc Health Med Ther., 9, 121-135. https://doi.org/10.2147/AHMT.S173115

Leuteritz, K., Friedrich, M., Nowe, E., Sender, A., Stöbel-Richter, Y., \& Geue, K. (2017). Life situation and psychosocial care of adolescent and young adult (AYA) cancer patients-Study for protocol of a 12-month prospective longitudional study. BMC Cancer, 17, 82. https://doi.org/10.1186/s12885-017-3077-z

Lewis, P., Mooney-Somers, J., \& Jordens, C. (2011). "I just want to help people": Complicating young cancer survivors' accounts of "being a better person". Tenth global conference on making sense of health, illness and disease. Oxford.

Marris, S., Morgan, S., \& Stark, D. (2011). 'Listening to Patients': What is the value of age-appropriate care to teenagers and young adults with cancer? Eur J Cancer Care, 20, 145-151. https://doi. org/10.1111/j.1365-2354.2010.01186.x

Maunsell, E., Lauzier, S., Brunet, J., Pelletier, S., Osborne, R. H,, \& Campbell, H. S. (2014). Health-related empowerment in cancer: Validity of scales from the Health Education Impact Questionnaire. Cancer, 120, 3228-3236. https://doi.org/10.1002/ cncr.28847

Miedema, B., Hamilton, R., \& Easley, J. (2007). From “invincibility” to "normalcy": Coping strategies of young adults during the cancer journey. Palliative a Supportive Care, 1, 4I-49.

Mirrielees, J. A., Breckheimer, K. R., White, T. A., Denure, D. A., Schroeder, M. M., Gaines, M. E., Wilke, L. G., \& Tevaarwerk, A.
J. (2017). Breast cancer survivor advocacy at a university hospital: Development of a peer support program with evaluation by patients, advocates, and clinicians. Journal of cancer education: the official journal of the American Association for Cancer Education, 1, 97-9104.

Morgan, S., Davies, S., Palmer, S., \& Plaster, M. (2010). Sex, drugs, and rock ' $n$ ' roll: Caring for adolescents and young adults with cancer. Journal of clinical oncology: official journal of the American Society of Clinical Oncology, 32, 4825-4830.

Mulcahy, C. M., Parry, D. C., \& Glover, T. D. (2010). The "patient patient": The trauma of waiting and the power of resistance for people living with cancer. Qualitative Health Research, 20, 10621075. https://doi.org/10.1177/1049732310369139

Murphy, D., Klosky, J. L., Reed, D. R., Termuhlen, A. M., Shannon, S. V., \& Quinn, G. P. (2015). The importance of assessing priorities of reproductive health concerns among adolescent and young adult patients with cancer. Cancer, 15, 2529-2536.

Osborne, R. H., Elsworth, G. R., \& Whitfield, K. (2007). The Health Education Impact Questionnaire (heiQ): An outcomes and evaluation measure for patient education and self-management interventions for people with chronic conditions. Patient Educ Couns., 66, 192-201. https://doi.org/10.1016/j.pec.2006.12.002

Power, S., \& Hegarty, J. (2010). Facilitated peer support in breast cancer: A pre- and post-program evaluation of women's expectations and experiences of a facilitated peer support program. Cancer Nursing, 2, E9-I6.

Quinn, G., Goncalves, V., Sehovic, I., Bowman, M., \& Reed, D. (2015). Quality of life in adolescent and young adult cancer patients: A systematic review of the literature. Patient Relat Outcome Meas., 6, 19-51. https://doi.org/10.2147/PROM.S51658

Reed, D. R., Oshrine, B., Pratt, C., Fridgen, O., Elstner, C., Wilson, L., Soliman, H., Lee, M. C., McLeod, H. L., Shah, B., Donovan, K. A., Pabbathi, S., Turney, M., Binitie, O., Healy, C., Nieder, M., Shaw, P. H., Galligan, A., Letson, G. D., Stern, M., Quinn, G. P., Davies, S. (2017). Sink or collaborate: How the immersive model has helped address typical adolescent and young adult barriers at a single institution and kept the adolescent and young adult program afloat. Journal of adolescent and young adult oncolog $\gamma, 4$, 503-5II.

Saxton, C., Amsellem, M., Buzaglo, J., \& Hollen, H. (2017). Supporting cancer treatment side effect management: Results from a national sample of cancer psychoeducation program attendees. American Public Health Association Annual Meeting, Atlanta, GA, November 4-8, 2017.

Shaw, P. H., Reed, D. R., Yeager, N., Zebrack, B., Castellino, S. M., \& Bleyer, A. (2015). Adolescent and young adult (AYA) oncology in the United States: A specialty in its late adolescence. Journal of pediatric hematology/oncology, 3, I6I-169.

Statistics Canada. (2019). Leading causes of death, total population, by age group. https://www150.statcan.gc.ca/t1/tbl1/en/tv.action?pid= 1310039401\&pickMembers\%5 B 0\%5D=2.23\&pickMembers $\% 5 \mathrm{~B} 1 \% 5 \mathrm{D}=3.1$

Tindle, D. A. (2015). Creating meaning: The cancer survivorship experiences of young adults in Australia, England and the United States [PhD]. School of Health and Biomedical Innovation. https:// eprints.qut.edu.au/82216/1/Danielle_Tindle_Thesis.pdf

Trevino, K. M., Abbott, C. H., Fisch, M. J., Friedlander, R. J., Duberstein, P. R., \& Prigerson, H. G. (2014). Patient-oncologist alliance as protection against suicidal ideation in young adults with advanced cancer. Cancer, 120, 2272-2281. https://doi.org/10.1002/ cncr.28740

Trevino, K. M., Fasciano, K., Block, S., \& Prigerson, H. G., (2013). Correlates of social support in young adults with advanced cancer. 
Supportive Care Cancer, 21, 421-429. https://doi.org/10.1007/ s00520-012-1536-2

Trevino, K. M., Fasciano, K., \& Prigerson, H. G. (2013). Patientoncologist alliance, psychosocial well-being, and treatment adherence among young adults with advanced cancer. $J$ Clin Oncol., 31, 1683-1689. https://doi.org/10.1200/JCO.2012.46.7993

Trevino, K. M., Maciejewski, P. K., Fasciano, K., Greer, J., Partridge, A., Kacel, E. L., Block, S., \& Prigerson, H. G. (2012). Coping and psychological distress in young adults with advanced cancer. The journal of supportive oncology, 3, I24-I30. https://doi.org/10.1016/j. suponc.2011.08.005

van den Berg, S. W., Van Amstel, F. K. P., Ottevanger, P. B., Gielissen, M. F., \& Prins, J. B., (2013). The cancer empowerment questionnaire: Psychological empowerment in breast cancer survivors. J Psychosoc Oncol., 31, 565-583. https://doi.org/10.1080/ 07347332.2013.825361

Warner, E. L., Fowler, B., Pannier, S. T., Salmon, S. K., Fair, D., Sparker-Perlman, H., Yancey, J., Randall, R. L., \& Kirchhoff, A. C., (2018). Patient navigation preferences for adolescent and young adult cancer services by distance to treatment location. $J$ Adolesc Young Adult Oncol., 7, 438-444. https://doi.org/10.1089/ jayao.2017.0124
Yennurajalingam, S., Rodrigues, L. F., Shamieh, O. M., Tricou, C., Filbet, M., Naing, K., Ramaswamy, A., Perez-Cruz, P. E., Bautista, M. J. S., Bunge, S., Muckaden, M. A., Fakrooden, S., Sewram, V., Tejedor, A. N., Rao, S. S., Williams, J. L., Liu, D. D., Park, M., Lu, Z., Cantu, H., Hui, D., Reddy, S. K., \& Bruera, E. (2017). Decisional control preferences among patients with advanced cancer: An international multicenter cross-sectional survey. Palliative Medicine, 4, 870-880.

Zebrack, B. J., Block, R., Hayes-Lattin, B., Embry, L., Aguilar, C., Meeske, K. A., Butler, M., \& Cole, S. (2013). Psychosocial service use and unmet need among recently diagnosed adolescent and young adult cancer patients. Cancer, 119, 201-214. https://doi. org/10.1002/cncr.27713

Zimmerman, M. A. (1995). Psychological empowerment: Issues and illustrations. Am J Community Psychol., 23, 581-599. https://doi. org/10.1007/BF02506983

Zucchetti, G., Bellini, S., Bertolotti, M., Bona, F., Biasin, E., Bertorello, N., Tirtei, E., \& Fagioli, F. (2017). Body image discomfort of adolescent and young adult hematologic cancer survivors. $J$ Adolesc Young Adult Oncol., 6, 377-380. https://doi.org/10.1089/ jayao.2016.0067 
Appendix 1

Interview Guide for Young Adults with Cancer

Thank you for accepting to be part of the interview.

The theme of this interview is health-related empowerment, so we are looking at what specifically makes you feel that you are able to deal with all the things that cancer has thrown at you and the ways in which you feel in control or the difficulties you face in feeling in control of your own health.

- Can you talk to me a bit about how you learned about your diagnosis and the kind of care you received?

- (if not discussed in previous answer) can you talk about any gaps in your care you experienced after your diagnosis?

- How would you describe your relationships with the medical team (i.e. nurses, physicians, physiotherapists, or any health care worker) who was involved in your care)?

- (if not discussed in previous answer) Can you share with me any positive or negative interactions you have had with medical professionals throughout your diagnosis and the impact that this has had on your experience with cancer?

- Can you talk a little bit about your sources of support?

- What do you feel you look for in your interactions with them and how have you felt so far?

- Whom do you feel are your most important sources of support (e.g., friends, family, support groups, colleagues, teachers)

- In experiencing illness, some people feel that certain things are empowering, so they help you feel in control, and some things are disempowering, can you talk about your encounters with the medical system and situations where you felt you were given a voice and situations where you felt you were silenced?

- (if patient self-advocacy not spoken about) Can you talk about instances where you felt you could advocate for your own care or situations where you felt it was impossible to speak about your own needs?

- Can you talk to me about the things you do to manage the symptoms you experience because of your cancer?

- How did you find these coping strategies?

- Some individuals feel that their experience of living with cancer prevents them from enjoying their life, how do you feel about this statement?

- When you think about having control over your illness, what does that mean to you?

- Can you describe if and how you think about having control over making decisions about the treatments that have been recommended to you?

- Can you think of a situation where you disagreed with the treatment recommended by your treating team and if so, how did you handle this situation? 
- Can you talk to me about any other supports that you have sought out on your own or other things that you have looked up to help you?

- (if not discussed in previous answer) Have you ever done complementary treatments and not spoken to your physician about them. If so, why didn't you speak to them about it?

- Can you think back to the time of your diagnosis and talk to me about how your sense of control (when it comes to health matters) may have evolved since then?

Thank you so much for sharing your time and story with us. Sharing your experience will help them learn about the issues young people living with cancer face on a daily basis. Our hope is to influence change in the services and care provided to young adults like you by sensitizing the community and creating public awareness. 